\title{
EL NUEVO PROCEDIMIENTO PARA LA INICIATIVA LEGISLATIVA Y EL EJERCICIO DE LA POTESTAD REGLAMENTARIA
}

\author{
Cayetano Prieto Romero \\ Asesor Técnico \\ Dirección General de Presupuestos y Recursos Humanos, Comunidad de Madrid
}

\begin{abstract}
RESUMEN
Este trabajo persigue una aproximación a los aspectos principales de la nueva regulación del procedimiento para la iniciativa legislativa y el ejercicio de la potestad reglamentaria, contenida en el título VI de la Ley 39/2015, de 1 de octubre, de Procedimiento Administrativo Común de las Administraciones Públicas. En particular, se destaca el nuevo esquema regulatorio integrado por las siguientes fases: planificación normativa, principios de buena regulación, motivación de la norma, participación ciudadana, publicación y evaluación posterior, que promueven una nueva cultura de calidad normativa.
\end{abstract}

Palabras clave: procedimiento normativo; mejora regulatoria; participación ciudadana; audiencia e información públicas.

\begin{abstract}
This article aims to approach the main aspects of the new regulation process for legislative initiative and regulatory power exercise, included in the Law 39/2015, of October $1^{\text {st }}$, on the Common Administrative Procedure of Public Administrations (Title VI). In particular, it focuses on the new regulatory scheme, comprising the following phases: regulatory planning, principles of better regulation, legislative motivation, citizen participation, publication and ex-post evaluation, which promote a new culture of regulatory quality.
\end{abstract}

Keywords: rule-making process; better regulation; citizen participation; public hearing. 


\section{SUMARIO}

I. Introducción.-II. Principios generales de la iniciativa LEgislativa y DE LA POTESTAD PARA DICTAR NORMAS CON RANGO DE LEY Y REGLAMENTOS.-III. LOS PRINCIPIOS DE BUENA REGULACIÓN: EVOLUCIÓN LEGISLATIVA: 1. Los principios de necesidad y eficacia. 2. El principio de proporcionalidad. 3. El principio de seguridad jurídica. 4. El principio de transparencia. 5. El principio de eficiencia. 6. El principio de estabilidad presupuestaria y sostenibilidad financiera.-IV. LA PARTICIPACIÓN DE LOS CIUDADANOS EN EL PROCEDIMIENTO DE ELABORACIÓN DE NORMAS: CONSULTA, AUDIENCIA E INFORMACIÓN PÚBLICAS: 1. La consulta pública. 2. La audiencia e información públicas. 3. Requisitos para la práctica de la consulta, audiencia e información públicas. 4. Supuestos excluidos de la realización de los trámites de consulta, audiencia e información públicas.-V. CONCLUSIONES.

\section{INTRODUCCIÓN}

La Ley 39/2015, de 1 de octubre, de Procedimiento Administrativo Común de las Administraciones Públicas (en adelante, LPAC) y la Ley 40/2015, de 1 de octubre, de régimen jurídico del sector público (en adelante, LRJ) ${ }^{1}$ constituyen, sin duda, dos piezas fundamentales del derecho administrativo recientemente actualizado ${ }^{2}$. Ambas forman parte de la reforma administrativa auspiciada e impulsada desde la Comisión para la Reforma de las Administraciones Públicas ${ }^{3}$ (en adelante, CORA), las dos habían sido propuestas para su actualización por su informe de 21 de junio de 2013, las dos se han aprobado a la par el día 1 de octubre de 2015, se han publicado en el Boletín Oficial del Estado del día siguiente y entran en vigor también a la par, un año después de su aprobación, sin perjuicio de algunas materias de ambas que demoran su entrada en vigor a momentos posteriores.

Sus respectivas exposiciones de motivos destacan los fundamentos comunes de ambas leyes, resaltados también en el informe CORA y antes en la Ley 2/2011, de 4 de marzo, de Economía Sostenible (en adelante, LES), que es el convencimiento de que una economía competitiva

1 La doctrina científica ha criticado la escisión de la regulación contenida en la Ley 30/1992, de 26 de noviembre, de Régimen Jurídico de las Administraciones Públicas y del Procedimiento Administrativo Común, en esos dos textos legales, la LPAC y la LRJ, puede verse al respecto J. A. SANTAMARÍA PASTOR (2016), «Reformas incompletas, proyectos de futuro: el régimen jurídico de las Administraciones Públicas y del Procedimiento Administrativo Común», en Revista Parlamentaria de la Asamblea de Madrid, 34, págs. 13-35.

2 Véase L. PAREJo Alfonso (2016), «A las puertas de su entrada en vigor: algunas cuestiones que suscitan las Leyes 39 y 40 de 2015, examinadas a la luz, en particular, de la autonomía local», en Revista Parlamentaria de la Asamblea de Madrid, 34, págs. 37-55.

3 La CORA fue creada mediante Acuerdo del Consejo de Ministros de 26 de octubre de 2012 . 
exige: «unas Administraciones Públicas eficientes, transparentes y ágiles», dice la exposición de motivos de la LPAC, o "unas Administraciones Públicas eficientes, transparentes, ágiles y centradas en el servicio a los ciudadanos y las empresas», dice la exposición de motivos de la LRJ. Es decir, ambas leyes se fundamentan en la necesidad de garantizar la competitividad de la economía y para ello introducen un nuevo procedimiento administrativo común y un nuevo régimen jurídico del sector público, en cuanto que herramientas que, en palabras del Plan Nacional de Reformas de 2014, permitirán racionalizar la actuación administrativa, mejorar la eficiencia en el uso de los recursos públicos y aumentar la productividad.

En concreto, la exposición de motivos de la LPAC describe el diagnóstico de la situación previa ${ }^{4}$ a su aprobación de la siguiente manera:

Los defectos que tradicionalmente se han venido atribuyendo a las Administraciones españolas obedecen a varias causas, pero el ordenamiento vigente no es ajeno a ellas, puesto que el marco normativo en el que se ha desenvuelto la actuación pública ha propiciado la aparición de duplicidades e ineficiencias, con procedimientos administrativos demasiado complejos que, en ocasiones, han generado problemas de inseguridad jurídica.

De acuerdo con ello, el artículo 1.1 precisa que su objeto es:

[...] regular los requisitos de validez y eficacia de los actos administrativos, el procedimiento administrativo común a todas las Administraciones Públicas, incluyendo el sancionador y el de reclamación de responsabilidad de las Administraciones Públicas, así como los principios a los que se ha de ajustar el ejercicio de la iniciativa legislativa y la potestad reglamentaria.

A esta segunda parte del objeto de la nueva regulación, contenida en su título VI, nos referiremos en el presente trabajo.

Sobre la iniciativa legislativa y la potestad normativa de las administraciones públicas, precisa la exposición de motivos que «recoge los principios» a los que habrá de ajustarse su ejercicio por la Administra-

\footnotetext{
4 «La realidad muestra un fenómeno de profusión, fugacidad y oscuridad de las normas, así como su improvisación, que podría en cierta medida atajarse mediante el adecuado desarrollo del procedimiento de elaboración que debería propiciar una actividad normativa reflexiva [...]», J. A. RAzQuin LizÁRRAGA (2007), «Hacia la calidad de las normas: la elaboración de los reglamentos", en el libro homenaje al profesor Francisco González Navarro, Organización y Procedimientos Administrativos, Thomson Aranzadi, pág. 239.

Véase también a J. J. Lavilla RubiRa (2009), «Los procedimientos de elaboración de los reglamentos en la Ley de Gobierno doce años después», en Revista Española de la Función Consultiva, págs. 17-29.
} 
ción titular, "haciendo efectivos los derechos constitucionales en este ámbito». En particular, la exposición de motivos destaca que las novedades introducidas van dirigidas a: i) incrementar la participación de los ciudadanos en el procedimiento de elaboración de normas, así, en concreto, el trámite de consulta ciudadana previa a la elaboración de la norma acerca de los problemas que se pretenden resolver con la iniciativa, la necesidad y la oportunidad de su aprobación, los objetivos de la norma y las posibles soluciones alternativas regulatorias y no regulatorias; ii) a mejorar la planificación normativa ex ante, a través del Plan Anual Normativo; iii) y a fortalecer la evaluación ex post, "puesto que junto con el deber de revisar de forma continua la adaptación de la normativa a los principios de buena regulación, se impone la obligación de evaluar periódicamente la aplicación de las normas en vigor, con el objeto de comprobar si han cumplido los objetivos perseguidos y si el coste y cargas derivados de ellas estaba justificado y adecuadamente valorado».

\section{PRINCIPIOS GENERALES DE LA INICIATIVA LEGISLATIVA Y DE LA POTESTAD PARA DICTAR NORMAS CON RANGO DE LEY Y REGLAMENTOS}

El artículo 127 se refiere en sus dos primeros párrafos a la iniciativa legislativa mediante la elaboración y aprobación de los anteproyectos de ley, que corresponde al Gobierno de la nación conforme a lo previsto en la Constitución, y a los órganos de gobierno de las comunidades autónomas de acuerdo con lo previsto en la Constitución y en sus respectivos Estatutos de Autonomía.

Asimismo, el apartado tercero alude a la facultad constitucionalmente reconocida al Gobierno de la nación, para aprobar normas con rango de ley: decretos leyes y reales decretos legislativos; y a los respectivos órganos de gobierno de las comunidades autónomas para aprobar normas equivalentes a aquellas en su ámbito territorial, de conformidad con lo establecido en la Constitución y en sus respectivos Estatutos de Autonomía.

En definitiva, en cuanto artículo introductorio del título VI no contiene ninguna novedad ${ }^{5}$, pues se limita a mencionar a los órganos a los que constitucionalmente, en el caso del Gobierno de la nación, y también conforme a los respectivos Estatutos de Autonomía, en el caso de los gobiernos autonómicos, corresponden ejercer la potestad para ini-

5 Véase J. A. Santamaría Pastor (2016), «Un nuevo modelo de ejercicio de las potestades normativas», en Revista Española de Derecho Administrativo, 175, págs. 31-55. 
ciar el procedimiento de elaboración de normas con rango de ley y para aprobar determinadas normas con rango de ley. Veamos:

a) La iniciativa legislativa del Gobierno de la nación se regula en los artículos 87 a 91 de la Constitución. En concreto, el artículo 87 determina los sujetos facultados para ejercer dicha iniciativa, entre los que se encuentran, además del Gobierno, el Congreso, el Senado, las asambleas legislativas de las comunidades autónomas y la iniciativa popular. Por lo tanto, conviene destacar que el título VI de la LPAC solo se refiere y regula la iniciativa legislativa gubernamental ${ }^{6}$, es decir, la que corresponde al Ejecutivo, no en cambio la atribuida a los demás sujetos citados en el mencionado precepto constitucional.

b) La facultad del Gobierno de la nación para aprobar normas con rango de ley: reales decretos leyes en casos de extraordinaria y urgente necesidad (artículo 86) y reales decretos legislativos en los casos de delegación recepticia (artículos 82 a 85).

c) La iniciativa legislativa de los órganos de gobierno de las comunidades autónomas en los términos establecidos en la Constitución y en sus respectivos Estatutos de Autonomía ${ }^{7}$. Por ejemplo, en el caso de la Comunidad de Madrid, según el artículo 15.2 de su Estatuto de Autonomía de 1983, la iniciativa legislativa corresponde a «los Diputados, a los Grupos Parlamentarios y al Gobierno, en los términos que se establezcan en el Reglamento de la Asamblea. Por Ley de la Asamblea se podrá regular el ejercicio de la iniciativa legislativa popular y de los Ayuntamientos...». El Reglamento de la Asamblea de Madrid regula el procedimiento legislativo en el título VI, reiterando en su artículo 139 los sujetos a los que según el Estatuto corresponde la iniciativa legislativa ante la Asamblea. Por su parte, el artículo 140, referente al procedimiento legislativo común, indica que «los proyectos de ley remitidos por el Consejo de Gobierno se presentarán de forma articulada e irán acompañados de los antecedentes necesarios para pronunciarse sobre ellos y precedidos de una exposición de motivos». Además, el artículo 150 , referente a las proposiciones de ley, indica que se «presentarán de forma articulada y precedidos de una exposición de motivos» y «las

\footnotetext{
${ }^{6}$ Respecto de los fundamentos constitucionales de la regulación de la iniciativa legislativa contenida en el título VI, puede verse el Dictamen del Consejo de Estado 275/2015, de 29 de abril, en particular el apartado III, letra B), 3.

7 El Dictamen del Consejo de Estado 275/2015, de 29 de abril, precisa sobre esto que: «Esta conclusión lleva a objetar, igualmente, la inclusión en el anteproyecto de la regulación de la iniciativa legislativa de las Comunidades Autónomas, respecto de la cual se plantean, además, problemas de constitucionalidad en algunos puntos, tal y como se examinará en el siguiente apartado (apartado III.C.4)».
} 
proposiciones de ley de iniciativa legislativa popular y los de los Ayuntamientos se presentarán además acompañados de los antecedentes necesarios para pronunciarse sobre ellos». Ello supone que la aplicación de las disposiciones contenidas en la LPAC requiere de la correspondiente adaptación normativa, en este caso, del Reglamento de la Asamblea de Madrid, para lo cual su disposición final quinta ofrece un plazo de un año a contar desde su entrada en vigor que, por lo tanto, finalizará el 2 de octubre de 2017.

d) La facultad de los órganos de gobierno de las comunidades autónomas de aprobar: i) normas con rango de ley en casos de extraordinaria y urgente necesidad, potestad que solo ha sido prevista en algunos Estatutos de Autonomía, no en todos, en concreto, en el caso de la Comunidad de Madrid, su Gobierno carece de dicha facultad; y ii) decretos legislativos en los casos de previa delegación de sus respectivos Parlamentos autonómicos, que tampoco ha sido contemplada en todos los Estatutos de Autonomía ${ }^{8}$. El Estatuto de Autonomía de la Comunidad de Madrid indica en su artículo 15.3 que «la Asamblea solamente podrá delegar la potestad de dictar normas con rango de ley en el Gobierno de acuerdo con lo establecido para el supuesto de delegación de las Cortes Generales en el Gobierno de la Nación, en los artículos 82, 83 y 83 de la Constitución».

Por su parte, el artículo 128 se refiere a la potestad reglamentaria que corresponde al Gobierno de la nación ex artículo 97 de la Constitución, a los órganos de gobierno de las comunidades autónomas de acuerdo con sus respectivos Estatutos de Autonomía y a los órganos de gobierno locales de acuerdo con la Ley 7/1985, de 2 de abril, reguladora de las Bases del Régimen Local.

Nótese que el título VI alude a la facultad para «dictar reglamentos y otras disposiciones», por su parte, el artículo 128 se titula con la expresión "potestad reglamentaria» y, además, su contenido emplea las siguientes expresiones: «ejercicio de la potestad reglamentaria», «los reglamentos y disposiciones administrativas» $\mathrm{y}$ "disposiciones administrativas». Las dudas que pueden derivarse del empleo de estas expresiones entendemos se resuelven con lo dispuesto en el primer apartado del artículo 128 que, claramente, comprende el ejercicio de la potestad reglamentaria del Gobierno de la nación, de los órganos de gobierno de las comunidades autónomas y de los órganos de gobierno locales, en definitiva, aunque con una redacción deficiente, dicho precepto se refiere

8 Véase J. A. SAntamaría PAStor (2016: 33). 
al «ejercicio de la potestad reglamentaria», es decir, a dicha potestad en su conjunto, comprensiva tanto de la iniciativa como de la instrucción o tramitación y de su contenido o resultado final. Y comprende también la potestad normativa de las entidades locales.

No obstante, respecto de las ordenanzas y reglamentos locales conviene precisar que no son fruto de la potestad reglamentaria, es decir, no son normas producidas por el ejecutivo, sino por el Pleno, que representa la soberanía popular. Por ello, las normas locales tienen una naturaleza jurídica distinta a los reglamentos ejecutivos ${ }^{9}$, sus relaciones con la ley vienen determinadas por el principio de vinculación negativa ${ }^{10}$ y su procedimiento de elaboración es también diferente al de un reglamento ejecutivo, por ejemplo, para este el trámite de consulta al Consejo de Estado u órgano consultivo de la respectiva comunidad autónoma es considerado como trámite esencial, en cambio, en el caso de las normas municipales dicho trámite no existe, aun en los casos en los que dichas normas desarrollen directamente una norma con rango de ley. Dicho esto, conviene tener en cuenta la generalidad de los contenidos del título VI, aplicable incluso a la iniciativa legislativa, de lo que se deduce un clara voluntad del legislador de incluir las normas locales en el ámbito de «los reglamentos y disposiciones administrativas» mencionadas en el artículo 128 y siguientes. Siendo así, a los exclusivos efectos del análisis del título VI, la expresión "potestad reglamentaria» comprende también la potestad normativa local y, en su caso, destacaremos las especialidades que correspondan.

No cabe duda que la vinculación del ejercicio de la potestad reglamentaria a las disposiciones del título VI es total, completa, como consecuencia del principio constitucional de jerarquía normativa. Así lo recuerda, además, el propio artículo 128.2 cuando dice, en aplicación de dicho principio, que «los reglamentos y disposiciones administrativas no podrán vulnerar la Constitución o las leyes...» y el apartado 3 de ese mismo precepto indica que «las disposiciones administrativas se ajustarán al orden de jerarquía que establezcan las leyes. Ninguna disposición administrativa podrá vulnerar los preceptos de otra de rango superior». La consecuencia de esa vulneración es la nulidad de pleno derecho del artículo 48.2 de la LPAC que dice: «También serán nulas de pleno derecho las disposiciones administrativas que vulneren la Constitución, las leyes u otras disposiciones administrativas de rango superior».

\footnotetext{
9 Véase A. Galán Galán (2001), La potestad normativa autónoma local, Barcelona: Atelier Libros.

10 Véase A. GaLÁn Galán (2010), «La consolidación del principio de vinculación negativa en el ámbito loca», en Revista Cemci, 8, julio-septiembre, págs. 1-27.
} 
En cambio, en el caso de infracción de las disposiciones del título VI en los procedimientos de iniciativa legislativa no parece que ello vaya a acarrear la nulidad de la ley que se apruebe posteriormente, salvo que dicha infracción legal tenga relevancia para la formación de la voluntad legisladora, tal y como ha expresado el Tribunal Constitucional en la Sentencia 84/2015 ${ }^{11}$. Es decir, las disposiciones del título VI sobre la iniciativa legislativa no conectan, al menos de forma evidente, con los títulos competenciales estatales del artículo $149.1 .18^{\mathrm{a}} \mathrm{CE}$, sino más bien con los de las comunidades autónomas vinculados a su autonomía política, no obstante, aun en el caso de que la norma adecuada establezca determinados requisitos formales o procedimentales para la elaboración de las leyes, su incumplimiento no acarrea su nulidad, como sucede en el caso de las disposiciones administrativas, salvo que, como ha reconocido el TC, dicha «infracción legal tenga relevancia para la formación de la voluntad legisladora».

Además, del principio de jerarquía normativa, el artículo 128.2 nos recuerda la vinculación de la potestad reglamentaria al principio de reserva de ley contenido en la Constitución y en los Estatutos de Autonomía. En concreto, precisa que: «Sin perjuicio de su función de desarrollo o colaboración con respecto a la ley, no podrán tipificar delitos, faltas o infracciones administrativas, establecer penas o sanciones, así como tributos, exacciones parafiscales $\mathrm{u}$ otras cargas o prestaciones personales o patrimoniales de carácter público». Lo que nos parece acertado, pero poco preciso de nuevo para el caso de las ordenanzas locales, a las cuales el Tribunal Constitucional ha reconocido un mayor margen de actuación para la tipificación de infracciones administrativas. Recuérdese que esta nueva doctrina constitucional motivó la aprobación del título XI de la Ley de Bases de Régimen Local de 1985, introducido en 2003 por la Ley 57/2003, de 16 de diciembre, de medidas para la modernización del gobierno local ${ }^{12}$. Por ello, la reciente LRJ, en sus artículos 25 y siguientes, referentes a los principios de la potestad sancionadora, precisa que la potestad sancionadora de las administraciones públicas «se ejercerá cuando haya sido expresamente reconocida por una norma con rango de ley, con aplicación del procedimiento previsto para su ejercicio y de acuerdo con lo establecido en esta Ley y en la Ley

11 «[... la doctrina de este Tribunal establece la necesidad de "examinar, ante todo, si se ha producido o no vulneración de la normativa reguladora de la elaboración de las leyes para, sólo después, y en su caso, valorar si aquella vulneración pudo tener relevancia para la formación de la voluntad legisladora" [STC 238/2012, de 13 de diciembre, FJ 2 a)] [...]» (Fundamento jurídico 4).

12 Véase la exposición de motivos de dicha Ley. 
de Procedimiento Común de las Administraciones Públicas y, cuando se trate de Entidades Locales, de conformidad con lo dispuesto en el Título $\mathrm{X}$ de la Ley 7/1985, de 2 de abril». Lo que se repite posteriormente, en su artículo 27, referente al principio de tipicidad: «Solo constituyen infracciones administrativas las vulneraciones del ordenamiento jurídico previstas como tales infracciones por una Ley, sin perjuicio de lo dispuesto para la Administración Local en el Título XI de la Ley 7/1985, de 2 abril».

En conclusión de esta parte, podemos decir que los contenidos de los artículos 127 y 128 de la LPAC solo reproducen determinados aspectos del régimen de la iniciativa legislativa y del ejercicio de la potestad reglamentaria que se regulan en otras normas, por lo que realmente no aportan nada nuevo a dicho régimen.

\section{LOS PRINCIPIOS DE BUENA REGULACIÓN: EVOLUCIÓN LEGISLATIVA}

Una de las novedades de esta nueva regulación contenida en el título VI respecto de la iniciativa legislativa y la potestad reglamentaria es la concreción de los principios de buena regulación como principios vinculantes en el ámbito de esa actividad administrativa, que el artículo 129.1 expresa diciendo que: «En el ejercicio de la iniciativa legislativa y la potestad reglamentaria, las Administraciones Públicas actuarán de acuerdo con los principios de necesidad, eficacia, proporcionalidad, seguridad jurídica, transparencia y eficiencia» ${ }^{13}$. Ciertamente estos principios ya se habían introducido en el derecho positivo, como veremos seguidamente, a través de la $\operatorname{LES}^{14}$ y la $\mathrm{LGUM}^{15}$, si bien por su incorporación a normas sectoriales parecían referidos, principalmente, a las normas de contenido económico o con incidencia en la unidad de mercado, ahora en la LPAC se enuncian, claramente, como principios de aplicación general con independencia de la materia - económica, social, sanitaria, etc.- que constituya el objeto de la regulación de que se trate.

Seguidamente el artículo 129.1 precisa el sentido o la finalidad de las exposiciones de motivos de los anteproyectos de las leyes o de los preámbulos de los proyectos de reglamentos que consiste en exponer o acreditar la adecuación de la norma a dichos principios, es decir, «[e]n la exposición

13 Véase J. A. Santamaría Pastor (2016: 35 y ss).

14 Véase el Dictamen del Consejo de Estado 275/2015.

15 El objetivo general de esta Ley, un marco regulatorio eficiente para las actividades económicas, trata de alcanzarse a través de una serie de técnicas de distinto contenido y alcance. Puede verse sobre ello J. Tornos MAs (2014), «La Ley 20/2013, de 9 de diciembre, de Garantía de la Unidad de Mercado. En particular, el principio de eficacia», en $R E A F, 19$, pág. 169. 
de motivos o en el preámbulo [...] quedará suficientemente justificada su adecuación a dichos principios». Lo que constituye una exigencia adicional a lo previsto, por ejemplo, en el Reglamento de la Asamblea de la Comunidad de Madrid que indica, como se ha visto supra, que los proyectos y proposiciones de ley irán "precedidos de una exposición de motivos», sin más, es decir, sin que tenga que pronunciarse como exige ahora la LPAC sobre los principios de buena regulación. Nótese que se exige, por un lado, que la justificación sobre la adecuación de la norma a los principios de buena regulación sea suficiente, es decir, debe quedar claramente expresada dicha adecuación y, por otro lado, que figure en la exposición de motivos o preámbulo, es decir, tendrá necesariamente su reflejo en la correspondiente memoria de análisis de impacto normativo ${ }^{16}$ (a la que no se refiere la LPAC), pero también debe tenerlo en la exposición de motivos. Se trata, por tanto, de una nueva forma de motivación que contribuirá sin duda a mejorar la calidad normativa ${ }^{17} \mathrm{y}$ abre unas posibilidades indefinidas de estructurar argumentos impugnatorios de las mismas en el marco del recurso directo o indirecto contra ellos ${ }^{18}$.

Algunos de esos principios son ampliamente conocidos, pues se trata de principios constitucionales, así el principio de seguridad jurídica contenido en el artículo 9.3, los de eficacia y eficiencia en el artículo 103 y el de transparencia en el artículo 105.b) de la Constitución. Dos son, por tanto, los principios mencionados en el artículo 129.1 que no tienen un reflejo directo en la Constitución, los de necesidad y proporcionalidad, y que, recordemos, han sido objeto de incorporación a nuestro derecho positivo a través de la Ley estatal 17/2009, de 23 de noviembre, sobre el libre acceso a las actividades de servicios y su ejercicio, de transposición de la Directiva 2006/123/CE, relativa a los servicios en el mercado interior, y reconocidos posteriormente como principios de la buena regulación económica en la LES y LGUM, de manera que la LPAC, según FERNÁNDEZ FARRERES, «no hace otra cosa que reiterar dichos principios, más allá de intrascendentes cambios en la redacción y denominación dada a los mismos» ${ }^{19}$.

16 Véase J. A. SAntamaría Pastor (2016: 44 y ss.).

17 «La necesaria motivación es, por tanto, una exigencia inexcusable de todo producto reglamentario, que ha de cumplirse a través de los informes obrantes en el expediente o en el preámbulo o exposición de motivos de cada reglamento. Ahora bien, esta obligada motivación ha de tener una determinada densidad, en el sentido de ser adecuada para justificar la alternativa y medidas contenidas en el reglamento y reflejar los aspectos relevantes del proceso de elaboración», J. A. RAzQUiN (2007: 243 y 244).

18 J. A. Santamaría Pastor (2016: 37).

19 G. Fernández Farreres (2016), «Las nuevas leyes de Régimen Jurídico del Sector Público y del Procedimiento Administrativo Común: entre la cosmética y el enredo», en Revista Parlamentaria de la Asamblea de Madrid, 34, págs. 55-74. 
Estos principios de buena regulación forman parte de las estrategias de mejora regulatoria o de calidad normativa, que RIVERO ORTEGA ha definido como «la revisión y modificación de los marcos normativos y técnicas de intervención para hacerlos más eficientes, compatibles con el principio de proporcionalidad y favorecedores de un equilibrio óptimo entre la creación de riqueza y la protección de los intereses públicos» ${ }^{20}$. Y constituyen un mandato dirigido a todas las administraciones públicas y sus organismos o entidades públicas vinculadas incluidas en el ámbito de aplicación de la LPAC, de manera que estas deberán respetarlos cuando ejerzan sus potestades normativas, es decir, no alteran la titularidad de dichas potestades pero suponen una injerencia en su ejercicio, por ejemplo, el Gobierno de una comunidad autónoma ejercerá libremente sus potestades normativas sobre el comercio minorista, si bien a la hora de ejercer dicha competencia y delimitar su contenido deberá respetar e incorporar los mandatos derivados de dichos principios.

En el ámbito de la Unión Europea ${ }^{21}$, el Informe Mandelkern de 2001 enumeraba como principios comunes de la buena regulación los siguientes: necesidad, proporcionalidad, subsidiariedad, transparencia, responsabilidad, accesibilidad y simplicidad.

En el caso de España, Dolors CANALs ${ }^{22}$ ha destacado como antecedentes de la reforma presente de la Administración Pública:

La política y estrategias de mejora regulatoria desarrolladas en Europa en los últimos lustros y más recientemente en España, y que engarzan con los objetivos de la Directiva de Servicios, orientados a la mejora de la competitividad de las pequeñas y medianas empresas. La reforma en este aspecto se proyecta a través de dos vías distintas pero complementarias: por una parte, a través de la desregularización impuesta por medidas legislativas transversales que afectan a cualquier tipo de actividad económica; y por otra, con una especie de regulación básica del procedimiento de elaboración de disposiciones

20 R. Rivero Ortega (2014), «Mejora regulatoria para la creación de PYMES en Castilla y León», en ídem (dir.), Mejora regulatoria, descarga burocrática y PYMES, Salamanca: Ratio Legis (págs. 13-49).

21 «La Comisión Europea, comprometida en los últimos tiempos con la mejora del entorno normativo de las empresas, juega también un papel primordial en esta política, fundamentalmente a partir del conocido Informe Mandelkern del 2001 y del Tratado de Lisboa, invitando a los Estados miembros, junto con las propias instituciones reguladoras, a considerarla en sus agendas y a ponerla en práctica. Con ello pretende mejorar la normativa europea y nacional para que no suponga un obstáculo a la actividad productiva y competitividad de las empresas, de las pequeñas y medianas empresas en especial», D. CANALS AMETLleR (2009), «Mejora normativa y reducción de cargas administrativas», Informe de las Comunidades Autónomas, 2009.

22 D. Canals Ametller (2014), «Reforma de la Administración Pública y unidad de mercado: incidencias en el régimen de intervención municipal en la actividad económica privada», en Cuadernos de Derecho Local (QDL), 28-46. 
generales —estatales, autonómicas e, incluso, locales- para incidir en su contenido normativo, a modo de «regulación de la regulación». Ambas vías se contemplan en la LGUM en aras, justamente, de la mejora normativa.

De forma esquemática, la regulación del ejercicio de la potestad normativa gubernamental se ha desarrollado de la siguiente manera:

a) En primer lugar, en 2009, en el ámbito de la Administración General del Estado, se introduce la memoria de análisis de impacto normativo mediante el Real Decreto 1083/200923, de 3 de julio, en desarrollo de la LG, que integra la memoria justificativa y de oportunidad de la propuesta, la memoria económica y el informe sobre el impacto por razón de género ${ }^{24}$, y su correspondiente guía metodológica ${ }^{25}$.

b) En segundo lugar, en 2011, la LES introdujo una serie de medidas para mejorar la calidad normativa, en concreto, estableció en su artículo 4 los principios de buena regulación que, aunque parecen referirse a las iniciativas normativas de carácter económico considerando el objeto su regulación, se enuncian en dicho artículo de forma general, resultando aplicables a todas las iniciativas normativas de todas las administraciones públicas ${ }^{26}$. Son los principios de necesidad, proporcionalidad, seguridad jurídica, transparencia, accesibilidad, simplicidad y eficacia. Por otra parte, en el artículo 5 concretó los instrumentos necesarios para garantizar la mejora de la calidad regulatoria, en particular, se refería a los instrumentos de análisis previo de iniciativas normativas, a la obligación de prestar la máxima atención al proceso de consulta pública y a la conveniencia de promover el desarrollo de procedimientos de evaluación posterior de su actuación normativa. Además, contemplaba la revisión periódica de la normativa vigente para adaptarla a los principios de buena regulación y a los objetivos de sostenibilidad, para lo cual se indicaba que, en el marco de la Conferencia Sectorial de Administración Pública, se acordarán e impulsarán criterios para promover la aplicación de los principios de buena regulación (artículo 6). Y, por último, también reconocía, de acuerdo con el principio de transparencia, la obligación de las administraciones públicas, excluidas las entidades locales,

23 Véase J. J. Lavilla Rubira (2009), «El procedimiento de elaboración de los reglamentos en la Ley del Gobierno doce años después», Revista Española de la Función Consultiva, págs. 17-29.

${ }^{24}$ P. ORTí Ferrer (2016), «Transparencia y buena regulación: el derecho de acceso a los expedientes normativos y la evaluación de impacto", en D. CANALS AMETLler, Datos. Protección, Transparencia y Buena Regulación, Girona: Documenta Universitaria, págs. 130 y ss.

${ }_{25}$ «Guía metodológica para la realización y estructuración de la memoria de análisis de impacto normativo", aprobada por el Consejo de Ministros de 11 de diciembre de 2009.

26 Así lo indicaba expresamente la exposición de motivos de la LES. 
de publicar un informe sobre las actuaciones de mejora regulatoria que hayan realizado (artículo 7). Estos preceptos contenidos en el capítulo I del título I eran de carácter básico conforme al artículo 149.1.18ª , según disponía su disposición final primera.

d) Posteriormente, en 2013, la LGUM establece una serie de garantías de las libertades de los operadores económicos, por ejemplo, la obligación que impone a las autoridades competentes de velar, en las disposiciones de carácter general ${ }^{27}$ que regulen una determinada actividad económica, por «la observancia de los principios de no discriminación, cooperación y confianza mutua, necesidad y proporcionalidad de sus actuaciones, eficacia en todo el territorio nacional de las mismas, simplificación de cargas y transparencia» ${ }^{28}$. Es decir, en el caso de que la disposición normativa propuesta tenga incidencia en el ámbito de la unidad de mercado conforme a la regulación contenida en aquella, se deberán considerar adicionalmente los contenidos y trámites establecidos en esa Ley.

Como ha afirmado Pernas García, la LGUM es en cierta medida el punto de llegada normativo que ha vivido nuestro ordenamiento jurídico-administrativo durante los últimos años: el desbordamiento de los principios y objetivos de la Directiva de Servicios y su extensión a todos los ámbitos sectoriales del derecho administrativo económico ${ }^{29}$.

En este sentido, por ejemplo, la LGUM exige la cooperación interadministrativa para el intercambio de la información relativa a los proyectos normativos que puedan tener incidencia en la unidad de mercado, "valorando especialmente la coherencia de dichos proyectos normativos con esta Ley», dicho intercambio se producirá de forma electrónica a través del sistema contemplado en su artículo 23. Por lo tanto, este intercambio se producirá como un trámite adicional en los procedimientos de elaboración de normas que afecten de manera relevante a la unidad de mercado, debiendo ponerse a disposición de las demás autoridades - la Administración General del Estado, las comunidades autónomas y las entidades locales-, con la antelación suficiente, el texto del proyecto de norma, acompañado de los informes o documentos que permitan su adecuada valoración, incluyendo en su caso la memoria del análisis de

27 La exposición de motivos de esa Ley dice: «[...] Todas las Administraciones Públicas observarán los principios recogidos en esta Ley, en todos sus actos y disposiciones y para todas las actividades económicas $[\ldots]$ ».

28 J. TORnOS Mas (2014).

29 J. PERnAS GARCÍA (2014), «El principio de necesidad y de proporcionalidad en la Ley de Garantía de la Unidad de Mercado», en M. J. Alonso MAS (dir.), El nuevo marco jurídico de la unidad de mercado, Madrid: La Ley, págs. 417-464. 
impacto normativo (artículo 14). Asimismo, exige a todas las autoridades competentes la evaluación periódica de su normativa al objeto de valorar su impacto en la unidad de mercado (artículo 15). La LGUM parte del principio general de libertad para el ejercicio y el establecimiento de actividades económicas (artículo 16), por ello en el caso de que se pretenda establecer un sistema de intervención administrativa mediante licencias, declaraciones y comunicaciones ${ }^{30}$ deberá justificarse en una razón imperiosa de interés general ${ }^{31}$ de la forma que se indica en el artículo 17. Estas obligaciones son de aplicación a todas las autoridades o administraciones públicas competentes, por lo tanto, también, en el ámbito de sus competencias, a las entidades locales ${ }^{32}$. Los preceptos mencionados tienen el carácter de normativa básica conforme a lo dispuesto en su disposición final cuarta.

En definitiva, como ha podido comprobarse, los principios de buena regulación concretados en el artículo 129.1 de la LPAC fueron reconocidos como tales por el artículo 4 de la LES, que, posteriormente, la LGUM los reconoce de forma específica en su capítulo II como «principios de garantía de la libertad de establecimiento y de la libertad de circulación». Es decir, nacen con una clara vocación de mejora del contexto económico y de la competitividad de las empresas, aunque se presentan como política de carácter transversal ${ }^{33}$, como normas básicas aplicables a todos los ámbitos, no solo a las disposiciones normativas de contenido económico ${ }^{34}$.

De esta forma, los artículos 4 a 7 de la LES han sido expresamente derogados por la disposición derogatoria única de la LPAC, integrándose sus contenidos en el título VI de esta Ley, y los correspondientes de la LGUM mantienen su vigencia en el ámbito de las actividades económicas. De manera que, insistimos, en este último supuesto, la «regulación de la regulación» vendrá determinada por las disposiciones generales

30 L. Cosculluela Montaner (2016), «El impacto del Derecho de la UE en la regulación española de la intervención administrativa en la actividad económica», en Revista Española de Administración Pública, págs. 103-120.

31 J. Pernas García (2014), la LGUM sigue el camino marcado por la Directiva de Servicios y la Ley Paraguas, que positivizaron, de forma restrictiva, la doctrina del TJUE sobre las razones imperiosas de interés general o las exigencias imperativas, como justificación a la restricción de las libertades económicas, y el contenido del test de proporcionalidad.

32 Véase en este sentido la redacción dada al artículo 84 bis de la Ley de Bases de Régimen Local de 1985, por la Ley 27/2013, de 27 de diciembre, de racionalización y sostenibilidad de la Administración Local.

33 D. Canals Ametller (2009), «Mejora normativa y reducción de cargas administrativas», Revista del Instituto de Derecho Público.

34 D. Canals Ametller (2016: 31), esta autora mantiene la opinión de que los principios de buena regulación que reproduce la Ley 39/2015, de 1 de octubre, son, por tanto, principios de buena regulación económica. 
contenidas en el título VI de la LPAC y por las específicas contenidas en la LGUM.

Antes de terminar esta breve descripción de la evolución legislativa de la mejora de calidad normativa, en general, y de los principios de buena regulación, en particular, conviene recordar que la exposición de motivos de la LPAC justifica su «regulación de la regulación» expresando, entre otras ideas, la necesidad de contar con una nueva regulación que termine con la dispersión normativa existente, refuerce la participación ciudadana, la seguridad jurídica y la revisión del ordenamiento. En resumen, establece el marco en el que debe desenvolverse la iniciativa legislativa y la potestad reglamentaria gubernamental, que permita:

a) Asegurar su ejercicio de acuerdo con los principios de buena regulación.

b) Garantizar de modo adecuado la audiencia y participación de los ciudadanos en la elaboración de las normas.

c) Lograr la predictibilidad y evaluación pública del ordenamiento.

\section{Los principios de necesidad y eficacia}

Estos principios son tratados conjuntamente en el apartado 2 del artículo 129, en cuya virtud, «la iniciativa normativa debe estar justificada por una razón de interés general, basarse en una identificación clara de los fines perseguidos y ser el instrumento más adecuado para garantizar su consecución».

La idea clave de estos principios se centra en la justificación de la iniciativa normativa, que será siempre una "razón de interés general», como ya expresara el artículo 4 de la LES — protección del medio ambiente, salud pública, seguridad ciudadana, defensa de los consumidores y usuarios, urbanismo, etc.- - Nótese que la expresión empleada «razón de interés de general» es más amplia que las utilizadas por la Ley 17/2009 y la LGUM de «razón imperiosa de interés general» necesaria para motivar los diferentes medios de intervención administrativa en la actividad económica de los ciudadanos y las empresas.

En nuestra opinión, la descripción de la razón de interés general perseguida por la norma proyectada debe contener una particularización de los concretos fines públicos perseguidos, que deben identificarse de forma clara en la propia norma, siendo esta el instrumento adecuado para garantizar su consecución. Es decir, los fines públicos perseguidos son una concreción o derivación de las razones de interés general que la 
motivan, debiendo explicitarse en la propia norma, de modo que no resultará suficiente con una vaga alusión a determinadas razones de interés general, sino que será necesario precisar los concretos fines públicos que se tratan de alcanzar con la regulación propuesta.

Por ejemplo, una norma que prohíba el tráfico de vehículos a motor en el centro de las ciudades se fundamentará en razones de interés general como la salud pública y la protección del medio ambiente, pues bien, esa norma tendrá que describir los concretos fines públicos que persigue - reducir los niveles de contaminación atmosférica, reducir los riesgos de padecer determinadas enfermedades o reducir los niveles de las que ya se padecen, reducir los daños al medio ambiente urbano, al patrimonio histórico-artístico, etc.- . Debe demostrar que es el mejor instrumento para garantizarlos, de modo que solo mediante la norma que se aprueba se podrá efectivamente establecer una prohibición de ese tipo, y, además, la prohibición de circular por el centro de las ciudades será la medida adecuada para garantizar la debida protección a la salud pública y el medio ambiente, mucho más efectiva que otras medidas alternativas como incentivar la compra de vehículos eléctricos, incentivar el uso del transporte público, desarrollar el carril bici, etc.

Esta idea de la adecuación conecta o se desarrolla a su vez con el principio de proporcionalidad, como se verá seguidamente.

\section{El principio de proporcionalidad}

Una vez justificada conforme a razones de interés general la necesidad de aprobar una determinada norma que, siguiendo con el ejemplo anterior, contenga una prohibición de circular vehículos a motor en el centro de la ciudad, y habiendo quedado debidamente motivada como el mejor instrumento para alcanzar los fines públicos perseguidos, en concreto, la salud pública y la protección del medio ambiente, el principio de proporcionalidad exige que la iniciativa que se proponga contenga «la regulación imprescindible para atender la necesidad a cubrir con la norma, tras constatar que no existen otras medidas menos restrictivas de derechos, o que impongan menos obligaciones a los destinatarios» (artículo 129.3).

Por lo tanto, el principio de proporcionalidad alude al contenido concreto de la propuesta normativa, que debe ser el «imprescindible» para alcanzar los fines públicos perseguidos. Es decir, puede establecerse la prohibición de circular por el centro de la ciudad todos los días, excepto los fines de semana, o bien, puede prohibir la circulación en 
determinados días laborables, o bien, puede establecer una prohibición parcial, es decir, unos días circulan los coches con número de matrícula par y los otros días los que tengan matrícula impar. En definitiva, determinar la medida que sea «imprescindible» para garantizar el fin público perseguido exige, como se ha explicado, una labor previa de valoración de las ventajas que ofrece la prohibición de circulación y las limitaciones que impone - la limitación del tráfico afecta a los negocios, a los trabajadores y a las personas en general.

De este modo, los principios de necesidad, eficacia y proporcionalidad conforman un modo distinto de justificar o motivar la aprobación de una nueva norma jurídica, digamos que pasamos de una motivación general y superficial a una motivación concreta y exigente, todo lo cual debe quedar claramente explicado en la memoria de análisis de impacto normativo. A partir de la entrada en vigor del título VI de la LPAC, no será suficiente con las memorias que contienen alusiones generales a la realización de determinados fines públicos, será necesario un mayor esfuerzo de concreción de las razones de interés general que motivan la norma, la concreción de los fines generales perseguidos, la adecuación de las medidas que se pretenden adoptar a la realización de esos fines y la definición de su contenido imprescindible, debiendo quedar justificado en la memoria que no existen otras alternativas menos restrictivas de los derechos o que imponga menos obligaciones a los ciudadanos, lo que se expresará, a su vez, de forma suficiente, en el preámbulo. Por lo tanto, siguiendo con el ejemplo anterior, la justificación de la prohibición de circular mediante vehículo a motor por las grandes ciudades requiere de una intensa labor de reflexión y argumentación de la adecuación de la prohibición o prohibiciones que se establezcan a los fines públicos perseguidos, en definitiva, de la memoria y del preámbulo debe deducirse claramente que la mejor forma de resolver el problema de la contaminación es regular esa prohibición.

La aplicación efectiva de estas disposiciones de garantía de la calidad de nuestras normas exige, sin duda, como se ha explicado supra, la adaptación de «la regulación de la regulación» de cada Administración Pública y de los reglamentos de sus respectivas asambleas legislativas.

Por otra parte, conviene destacar que esta exigencia de motivación aparece reforzada en el artículo 4 de la LRJ para los casos en los que se limite el ejercicio de los derechos individuales o colectivos o se exija el cumplimiento de requisitos para el desarrollo de una actividad, que dice:

Las Administraciones Públicas que, en el ejercicio de sus respectivas competencias, establezcan medidas que limiten el ejercicio de derechos indivi- 
duales o colectivos o exijan el cumplimiento de requisitos para el desarrollo de un actividad, deberán aplicar el principio de proporcionalidad y elegir la medida menos restrictiva, motivar su necesidad para la protección de interés público así como justificar su adecuación para lograr los fines que se persiguen, sin que en ningún caso se produzcan diferencias de trato discriminatorias. Asimismo deberán evaluar periódicamente los efectos y resultados obtenidos.

Este precepto que reproduce el contenido del artículo 39 bis de la ya derogada LRJPAC, se refiere a cualquier actuación que desarrollen las administraciones públicas en el ejercicio de sus competencias, sean o no normativas, que ahora figura como un principio general que guía la actuación administrativa en los supuestos de intervención en el ejercicio de los derechos de los ciudadanos o en la exigencia de requisitos para el desarrollo de una actividad — sea o no económica.

En el caso de que se trate de actividades económicas, ha de considerarse, además, como también se ha explicado supra, que la LGUM establece determinadas restricciones al posible contenido de la norma, de manera que, según su artículo 16, el acceso a las actividades económicas y su ejercicio será libre en todo el territorio nacional y solo podrá limitarse conforme a lo establecido en dicha Ley y a lo dispuesto en la normativa de la Unión Europea o en tratados y convenios internacionales. Añadiendo en el artículo 17 las reglas que deben seguirse en el supuesto de que la norma pretenda someter la actividad regulada a algún tipo o medio de intervención administrativa previa (licencia) ${ }^{35}$ o posterior (declaración responsable o comunicación), en cuyo caso deberá justificarse de acuerdo con los principios de necesidad y proporcionalidad tal como se indica en ese precepto, es decir, en este caso, no sirve explicitar cualquier razón de interés general ${ }^{36}$, como exige el artículo 129.2 LPAC, sino que deberá motivarse, dependiendo del supuesto de que se trate, en alguna de las razones que expresamente se indica en ese artículo ${ }^{37}$ (por ejemplo, protección del medio ambiente, razones de orden público,

\footnotetext{
35 Véase S. Muñoz Machado (2014: prólogo).

36 Respecto de la motivación en una razón imperiosa de interés general véase la sentencia del Tribunal Supremo, de 29 de junio de 2011, Sala de lo Contencioso-Administrativo, Sección $3^{\mathrm{a}}$, RJ $2011 \backslash 6038$.

37 «La LGUM restringe las razones imperiosas de interés general o exigencias imperativas que el TJUE ha considerado como justificativas de restricciones autorizatorias a las libertades de circulación económica, [...]. Así, la redacción actual [...] considera que el establecimiento de un régimen autorizatorio es necesario, está justificado, cuando concurren razones de orden público, seguridad pública, salud pública, protección del medio ambiente, o cuando la escasez de recursos naturales o la existencia de inequívocos impedimentos técnicos limiten el número de operadores económicos del mercado», J. PERnAS GARCIA (2014: 431).
} 
seguridad pública o salud pública en el lugar concreto en el que se realiza la actividad, para el caso de exigirse licencia previa a los operadores económicos).

\section{El principio de seguridad jurídica}

De acuerdo con lo dispuesto en el artículo 129.2 del principio de seguridad jurídica se derivan las siguientes exigencias.

En primer lugar, la iniciativa normativa se ejercerá de manera coherente con el resto del ordenamiento jurídico, nacional y de la Unión Europea, para generar un marco normativo estable, predecible, integrado, claro y de certidumbre, que facilite su conocimiento y comprensión $\mathrm{y}$, en consecuencia, la actuación y toma de decisiones de las personas y empresas. El ejercicio coherente con el resto del ordenamiento jurídico apuntado es una exigencia del principio de jerarquía normativa y del principio de competencia que guían las relaciones entre los diferentes ordenamientos. Por su parte, a la idea de un marco normativo predecible contribuye la técnica de la planificación normativa prevista en el artículo 130, pues, permite el conocimiento anticipado de la intención gubernamental de regular determinadas materias. Y en punto al marco jurídico integrado, claro y de certidumbre, parece una obviedad que conviene resaltar considerando la práctica legislativa consistente en leyes ómnibus, leyes de medidas, decretos leyes, etc., que modifican múltiples leyes, dificulta sobremanera dichos valores y, a su vez, complica su conocimiento y compresión por la ciudadanía y las empresas. Otras veces dicha dificultad deriva de una mala práctica normativa, por ejemplo, la que consiste en mantener la vigencia de una ley que ha sido modificada parcialmente en multitud de ocasiones, sin que se apruebe un texto refundido o una nueva ley que incorpore todos esos cambios; o la consistente en no adaptar a la nueva legislación estatal básica la normativa autonómica. Esperamos, por lo tanto, que efectivamente esos principios contribuyan a una mejora de la calidad normativa. En este sentido, conviene recordar las reflexiones contenidas en el Informe Mandelkern sobre el principio de simplicidad: "El objetivo debería ser el de conseguir que cualquier normativa sea simple de utilizar y entender, ya que este es un prerrequisito esencial si los ciudadanos desean hacer un uso eficaz de los derechos que les han sido concedidos: la normativa debería ser tan detallada como fuera necesario y tan simple como fuera posible».

En segundo lugar, cuando en materia de "procedimiento administrativo» la iniciativa normativa establezca trámites adicionales o distin- 
tos a los contemplados en esta Ley, estos deberán ser justificados atendiendo a la singularidad de la materia o a los fines perseguidos por la propuesta. A esto se refiere el artículo 1.2 de la LPAC, que reserva a la ley la inclusión «de trámites adicionales o distintos de los previstos en esta Ley», siempre y cuando "resulte eficaz, proporcionado y necesario para la consecución de los fines propios del procedimiento, y de manera motivada», motivación que deberá argumentarse conforme a la singularidad de la materia o a los fines perseguidos por la norma proyectada. La exposición de motivos de la LPAC no concreta a qué tipo de trámites se está queriendo referir la expresión «trámites adicionales o distintos», aunque parece referirse a trámites no regulados o previstos en la propia LPAC. Por su parte, el Consejo de Estado utiliza como ejemplo de ello la evaluación de impacto ambiental, que efectivamente no se encuentra prevista en la LPAC de forma expresa, por tratarse más bien de un procedimiento administrativo ratione materiae que, a su vez, es instrumental del procedimiento de aprobación de planes y programas, de autorización de proyecto o de proyectos y de control de los proyectos sometidos a declaración responsable y comunicación previa, y cuya función es la de analizar los posibles efectos significativos sobre el medio ambiente de los planes, programas y proyectos, tal y como lo define el artículo 5 de la Ley 21/2013, de 9 de diciembre, de evaluación ambiental.

En tercer lugar, las habilitaciones para el desarrollo reglamentario de una ley serán conferidas, con carácter general, al Gobierno o Consejo de Gobierno respectivo. La atribución directa a los titulares de los departamentos ministeriales o de las consejerías del Gobierno, o a otros órganos dependientes o subordinados de ellos, tendrá carácter excepcional y deberá justificarse en la ley habilitante ${ }^{38}$.

En cuarto lugar, las leyes podrán habilitar directamente a autoridades independientes $\mathrm{u}$ otros organismos que tengan atribuida esta potestad para aprobar normas en desarrollo o aplicación de las mismas, cuando la naturaleza de la materia así lo exija.

\section{El principio de transparencia}

El principio de transparencia aplicado al ámbito de la iniciativa legislativa y del ejercicio de la potestad reglamentaria exige a las administraciones públicas, conforme a lo dispuesto en el artículo 129.5, conlleva:

38 Esta previsión atiende a una sugerencia formulada por el Consejo de Estado en el Dictamen 275/2015. 
- Posibilitar el acceso sencillo, universal y actualizado a la normativa en vigor y a los documentos propios de su proceso de elaboración, en los términos establecidos en el artículo 7 de la Ley 19/2013, de 9 de diciembre, de transparencia, acceso a la información pública y buen gobierno. Se trata, por un lado, de facilitar el acceso de todos a la normativa en vigor actualizada, lo cual no siempre se encuentra garantizado, en particular, en el caso de las comunidades autónomas y de las entidades locales, lo que incide de forma negativa en el principio de seguridad jurídica, pues, en determinadas ocasiones, el acceso a la norma en vigor resulta verdaderamente una ardua tarea, para ello es importante que las administraciones públicas impulsen o fortalezcan los servicios propios dedicados a prestar este servicio. Por otra parte, se trata también de permitir el acceso a los documentos empleados en el proceso de elaboración de la norma, lo que contribuye a su comprensión y, por lo tanto, facilita su cumplimiento efectivo. Esta última previsión viene a reiterar lo ya contemplado en ese artículo 7, «información de relevancia jurídica», que forma parte de los contenidos de la "publicidad activa».

- Definir claramente los objetivos de las iniciativas normativas y su justificación en el preámbulo o exposición de motivos. Lo que, como hemos visto supra, también exige el apartado 1 del artículo 129.

- Posibilitar que los potenciales destinatarios tengan una participación activa en la elaboración de las normas. Lo que, como luego se verá, se desarrolla de forma concreta en el artículo 133 mediante consulta, audiencia e información públicas.

\section{El principio de eficiencia}

«En aplicación del principio de eficiencia, la iniciativa normativa debe evitar cargas administrativas innecesarias o accesorias y racionalizar, en su aplicación, la gestión de los recursos públicos» (artículo 129.6).

Sobre esta idea conviene recordar que en los últimos años las administraciones públicas en el ámbito de la Unión Europea, la Administración General del Estado, las comunidades autónomas y las entidades locales han desarrollado de forma más o menos intensa planes de reducción de cargas administrativas, así como de medidas de simplificación administrativa, que han exigido para su efectiva aplicación la adaptación o modificación de las correspondientes normas legales y reglamentarias, con el objetivo principal de mejorar el contexto económico. 
En concreto, en el caso de la Administración General del Estado, la memoria de análisis de impacto normativo regulada en el artículo 26.3 de la LG deberá contener un apartado referente a la identificación de «las cargas administrativas que conlleva la propuesta» y «se cuantificará el coste de su cumplimiento para la Administración y los obligados a soportarlas con especial referencia al impacto sobre las pequeñas y medianas empresas». A su vez, asigna al Ministerio de la Presidencia la competencia para velar por el cumplimiento de este principio de eficiencia, debiendo analizar respecto de cada proyecto normativo «el cumplimiento o congruencia de la iniciativa con los proyectos de reducción de cargas administrativas o buena regulación que se hayan aprobado en disposiciones y acuerdos de carácter general para la Administración General del Estado» (artículo 26.9).

\section{El principio de estabilidad presupuestaria y sostenibilidad financiera}

Este principio no figura expresamente mencionado en el apartado 1 del artículo 129, pero sí en su apartado 7, que indica que: «Cuando la iniciativa normativa afecte a los gastos o ingresos públicos presentes o futuros, se deberán cuantificar y valorar sus repercusiones y efectos, y supeditarse al cumplimiento de los principios de estabilidad presupuestaria y sostenibilidad financiera». Se trata del contenido "presupuestario» de la memoria de análisis de impacto normativo que incluirá, en el caso de la Administración General del Estado, según el artículo 26.3 de la LG, el análisis del «impacto económico y presupuestario», que comprende, por un lado, la evaluación de «las consecuencias de su aplicación sobre los sectores, colectivos o agentes afectados por la norma, incluido el efecto sobre la competencia, la unidad de mercado y la competitividad y su encaje con la legislación vigente en cada momento sobre estas materias. Este análisis incluirá la realización del test Pyme de acuerdo con la práctica de la Comisión Europea». Y, por otro lado, el análisis estrictamente presupuestario que de forma específica debe comprender la incidencia de la norma proyectada en los ingresos y gastos públicos, en particular, en los gastos de personal al servicio del sector público, debiendo supeditarse al cumplimiento de los principios de estabilidad y sostenibilidad financiera.

Como conclusión de esta parte, podemos destacar, por un lado, la exigencia de que la exposición de motivos o preámbulo de la norma incorpore, como motivación de su contenido, las explicaciones necesarias sobre la realización de los principios de buena regulación, es decir, 
debe explicarse la necesidad, eficacia, proporcionalidad, etc., del nuevo contenido normativo, lo que, sin duda, supone un importante cambio de cultura administrativa, pues pasamos de una poco exigente con dicha motivación a otra más coherente con la buena gobernanza que, por otro lado, comprende la necesidad de aprobar solo aquellas normas que resulten claramente necesarias, eficaces, proporcionadas, respetuosas con el principio de seguridad jurídica, en las que se haya dado participación efectiva a los ciudadanos y las empresas afectadas. Lo que contribuirá a garantizar los derechos de los ciudadanos y las empresas y la eficacia del interés general.

\section{LA PARTICIPACIÓN DE LOS CIUDADANOS EN EL PROCEDIMIENTO DE ELABORACIÓN DE NORMAS: CONSULTA, AUDIENCIA E INFORMACIÓN PÚBLICAS}

El artículo 133 contiene la regulación básica de la participación de los ciudadanos ${ }^{39}$ en el procedimiento de elaboración de normas con rango de ley y reglamentos. En concreto, regula los trámites de audiencia e información públicas, conocidos por todos y respecto de los cuales existe una práctica administrativa consolidada y una abundante jurisprudencia del $\mathrm{TS}^{40}$, derivados del principio de participación ciudadana previsto en el artículo 105.a) de la CE, que reserva a la ley la regulación de «la audiencia de los ciudadanos, directamente o a través de las organizaciones y asociaciones reconocidas por la ley, en el procedimiento de elaboración de las disposiciones administrativas que les afecten». Esta regulación, además, es la primera regulación básica aprobada en la materia $^{41}$, lo que constituye en sí mismo una novedad.

39 Véase A. J. Alonso Timón (2016), «La participación ciudadana, transparencia y técnica normativa en las Leyes 39 y 40 de 2015. Los principios de buena regulación», en Revista Parlamentaria de la Asamblea de Madrid, 34, págs.76-102.

40 Véase también P. SALA AtiEnZa (2008), «El trámite de audiencia en la elaboración de los reglamentos según la jurisprudencia del Tribunal Supremo», en RAP, 177, págs. 247-263.

41 Recuérdese que la LRJPAC dedicaba sus artículos 51 y 52 a la regulación de los principios referidos a las disposiciones administrativas, en concreto, el artículo 51 se refería a los principios de jerarquía y competencia, y el artículo 52 a los principios de publicidad e inderogabilidad singular. Anteriormente, la Ley de Procedimiento Administrativo de 1958 regulaba el procedimiento de elaboración de disposiciones de carácter general en los artículos 129 a 132, que no fueron derogados por aquella Ley, sino por la Ley del Gobierno de 1997. 


\section{La consulta pública}

La exposición de motivos apunta que el título VI incluye entre sus novedades diferentes trámites para incrementar la participación de los ciudadanos en el procedimiento de elaboración de normas, entre las que destaca la «consulta pública» que se practicará con carácter previo ${ }^{42}$ a la elaboración de la norma, a fin de recabar «la opinión de ciudadanos y empresas acerca de los problemas que se pretenden solucionar con la iniciativa, la necesidad y oportunidad de su aprobación, los objetivos de la norma y las posibles soluciones alternativas regulatorias y no regulatorias».

Por lo tanto, no se trata solo, como hasta ahora, de someter el proyecto normativo a esos trámites de audiencia e información públicas, sino de efectuar una consulta anterior ${ }^{43}$ a la elaboración del proyecto, que tendrá por finalidad específica recabar la opinión de los «sujetos y de las organizaciones más representativas potencialmente afectados» por la futura norma acerca de:

a) Los problemas que se pretenden solucionar con la iniciativa.

b) La necesidad y oportunidad de su aprobación.

c) Los objetivos de la norma.

d) Las posibles soluciones alternativas regulatorias y no regulatorias $^{44}$.

La Administración debe asegurarse mediante este trámite, en los casos que proceda, como luego se verá, que la norma que pretende aprobar es necesaria y oportuna, no existiendo una posible solución no regulatoria, lo que constituye la finalidad esencial de este trámite, pero también lo es del procedimiento en su conjunto, orientado a garantizar el acierto y legalidad de la norma proyectada. Esta idea conecta, a su vez, con los principios de buena regulación, en particular, con los de necesidad y eficacia, recordemos que, en virtud de estos principios, «la iniciativa normativa debe estar justificada por una razón de interés

42 D. Canals Ametller (2016: 29-30).

43 Joaquín Meseguer Yebra (2016), «Procedimiento de elaboración de normas y better regulation en el ejercicio de la potestad reglamentaria local», en C. CAMPos AcuÑA (dir.), El nuevo procedimiento administrativo local tras la Ley 39/2015, Wolters Kluwer.

44 J. A. Santamaría Pastor (2016: 41-42), pero formular y someter a consulta tales presupuestos es un método racionalizador de tan indiscutible utilidad como de difícil implantación; entre otras razones, porque la elaboración de un texto suele partir de una idea de absoluta simplicidad acerca de un problema concreto, de manera que los objetivos, los medios para conseguirlos y las alternativas surgen solo al hilo del trabajo de redacción material de un documento articulado. 
general, basarse en una identificación clara de los fines perseguidos y ser el instrumento más adecuado para garantizar su consecución» (artículo 129.2). Por esta razón, nos parece que este trámite es más orientativo que definitivo, pues lo que inicialmente puede resultar justificado puede no estarlo después y viceversa, por ello no parece razonable su consideración como un trámite esencial, pues su finalidad puede lograrse por otros trámites posteriores de modo que su omisión puede ser subsanada a lo largo de la tramitación del procedimiento. Sobre esto volveremos más adelante.

La consulta pública se practicará, como indica el artículo 133.1, a través del portal web de la Administración competente, al igual que, como luego veremos, la audiencia y la información públicas (artículo 133.2), que desplaza definitivamente la publicación en diarios o boletines oficiales, sin perjuicio de que actúen como medios de difusión complementarios de aquel.

Siendo este el breve régimen jurídico básico de la consulta pública establecido en el primer párrafo del artículo 133, podemos plantearnos las siguientes cuestiones:

- ¿Qué sucede si no se práctica este trámite, ello acarrea sin más la nulidad de la norma o puede entenderse subsanada su omisión con la práctica del posterior trámite de audiencia? En principio, hemos de considerar, conforme a la jurisprudencia del Tribunal Supremo, que la omisión del procedimiento de elaboración de normas que constituya «una inobservancia transcendente» para el cumplimiento de la finalidad a que tiende su exigencia, arrastra la nulidad de la norma. Asimismo:

[...] ha insistido en la necesidad de efectuar una interpretación funcional y teleológica de las garantías procedimentales establecidas para la elaboración de disposiciones generales, que se justifican no por el puro formalismo de su realización sino por la finalidad a que responden, en cuya valoración han de tenerse en cuenta las especialidades de la disposición general de que se trate [...] (Sala de lo Contencioso-Administrativo, Sección 4a , Sentencia de 9 noviembre 2005).

En nuestra opinión, la valoración de la omisión de la consulta previa requiere considerar dos ideas: una, que se trata de un trámite previo al procedimiento de elaboración normativa; y dos, que su finalidad puede alcanzarse mediante otros trámites posteriores, por ejemplo, a través de la participación de los sujetos y de las organizaciones más representativas potencialmente afectadas en el trámite de audiencia o de infor- 
mación públicas, donde podrán pronunciarse sobre la necesidad y la oportunidad de la concreta norma proyectada, de la existencia o no de alternativas no regulatorias, etc. Lo que nos lleva a considerar que se trata propiamente de un trámite duplicado del trámite de audiencia e información pública, aunque el primero se refiera a ideas generales del futuro proyecto y el segundo se efectúe respecto del concreto contenido del proyecto normativo ya elaborado. Siendo así, parece razonable entender conforme al principio de eficacia administrativa y de economía procesal que la omisión de ese trámite no constituirá una «inobservancia trascendente», siempre y cuando quede subsanado mediante la práctica posterior del trámite de audiencia e información públicas ${ }^{45}$.

- ¿Qué sucede si el resultado de la consulta es negativo, es decir, si se deduce que la propuesta no es necesaria ni oportuna, por ejemplo, porque exista otra solución alternativa no regulatoria? En nuestra opinión, parece que el precepto obliga a practicar el trámite de consulta a la ciudadanía, pero no establece que el resultado sea vinculante para la Administración, sin perjuicio de que en la memoria de análisis de impacto normativo deba explicitarse las razones que han motivado la desestimación de las observaciones formuladas en dicho trámite. Respecto de lo cual todavía los interesados tendrán ocasión de pronunciarse en el trámite de audiencia e información púbicas, eso sí ya sobre la base de una propuesta concreta definida en el proyecto.

En definitiva, considerando que el trámite de consulta pública es previo al propio procedimiento de elaboración de la disposición administrativa y que su finalidad puede realizarse también a través de otros trámites similares, podemos concluir que su omisión no constituirá una «inobservancia trascendente» que afecte a la finalidad perseguida por la norma, siempre que se haya realizado a través del trámite de audiencia o información públicas, pues así se habrá logrado su finalidad a pesar de dicha omisión. Siendo así, nos parece que este trámite debería haberse configurado en la LPAC con carácter facultativo, que es, por otro lado, el carácter propio de las actuaciones anteriores al inicio del procedimiento, de modo que la Administración pudiera decidir en atención a

45 «Ahora bien, como pone de manifiesto Martín Rebollo, el cumplimiento debido del trámite de información pública no exime de la necesaria audiencia a los interesados, salvo cuando la información pública haya permitido a las entidades representativas las mismas posibilidades que les otorga la audiencia, esto es, la oportunidad de exponer su parecer en razonado informe, a la vista del proyecto y no de cualquier otro documento de trabajo, y en el plazo mínimo que prescribe la Ley para el cumplimiento de la audiencia», J. M. RodríGuez MuÑoz (2011), «Tratamiento de los defectos en el procedimiento de elaboración de reglamentos, con especial referencia a la Comunidad Autónoma de Extremadura», Revista Española de la Función Consultiva, pág. 209. 
las características de la futura norma la conveniencia o no de recabar la opinión de los ciudadanos y de las organizaciones más representativas potencialmente que pudieran verse afectadas.

\section{La audiencia e información públicas}

Sin perjuicio de la consulta previa a la redacción del texto del proyecto normativo, dice el artículo 133.2 que cuando la norma "afecte a los derechos e intereses legítimos de las personas», se publicará con el objeto de dar audiencia a los ciudadanos afectados (trámite de audiencia) y se recabará cuantas aportaciones adicionales puedan hacerse por otras personas o entidades (trámite de información pública). «Asimismo», continúa diciendo dicho precepto, «podrá también recabarse directamente la opinión de las organizaciones o asociaciones reconocidas por ley que agrupen o representen a las personas cuyos derechos o intereses legítimos se vieren afectados por la norma y cuyos fines guarden relación directa con su objeto». La idea principal que se deriva de esta regulación es que cuando la propuesta afecte a los derechos e intereses legítimos de las personas debe convocarse trámite de audiencia y de información públicas y, además, puede convocarse a las organizaciones o asociaciones representativas, esquema que se diferencia del anterior previsto en el artículo 24 de la LG.

La función de estos trámites ${ }^{46}$, al permitir la participación ciudadana en el procedimiento de elaboración de las disposiciones administrativas, es reforzar el principio democrático, la legitimidad democrática de la norma, la defensa de los derechos e intereses concretos y particulares afectados y mejorar «la eficacia, la calidad de las normas y su legalidad ${ }^{47}$.

Es decir, una vez elaborado el proyecto, conforme a su contenido, puede darse dos circunstancias:

46 Para González Pérez - Comentarios a la Ley de Régimen Jurídico de las Administraciones Públicas y del Procedimiento Administrativo Común (Ley 30/1992, de 26 de noviembre), tomo I, $3^{\text {a }}$ ed., Madrid: Civitas- son trámites que obedecen a finalidad distinta y están sometidos a distinto régimen jurídico los de información pública y audiencia y vista a los interesados. Mientras el primero es el cauce formal de la participación ciudadana — para que cualquiera pueda aportar cuantas sugerencias y datos contribuyan al acierto de la disposición general一, el segundo trata de dar oportunidad a los que ostenten la condición de interesados de defender sus derechos o intereses legítimos. En la información pública domina la idea de la garantía del interés público, y en el segundo la de la garantía de los derechos e intereses de los particulares (págs. 1491 y 1492).

47 E. Melero Alonso (2005: 375). 
i) Que el proyecto afecte a los derechos e intereses legítimos de los ciudadanos, en cuyo caso el trámite de audiencia es obligatorio ${ }^{48} 49$, conforme a lo dispuesto en el artículo 105.a) de la CE. Constituye por tanto un requisito esencial para la validez del resultado del procedimiento que tiene por objeto no solo que los interesados hagan valer la defensa de los derechos e intereses que corresponda sino también facilitar el acierto en la elaboración de la disposición ${ }^{50}$.

De acuerdo con lo previsto en el artículo 133.2 en estos casos de afectación a los derechos e intereses legítimos de las personas, se deberá practicar con carácter preceptivo el trámite de audiencia y de información públicas. La audiencia se efectuará de forma directa a los concretos afectados y también, adicionalmente, a las organizaciones y asociaciones reconocidas por la ley que las agrupen o representen.

ii) Que el contenido del proyecto no afecte en los derechos e intereses legítimos de los ciudadanos. En este caso, la Administración podía, «cuando la naturaleza de la disposición lo aconseje», decía el inciso final de su artículo 24.1.c) de la LG, someter su contenido al trámite de información pública. Dicho trámite resultaba por lo tanto facultativo. Precisión que ha desaparecido del nuevo artículo 133.2, que no alude de forma directa a las disposiciones administrativas que no afecten a los derechos e intereses legítimos de los ciudadanos, salvo lo indicado en su apartado 4 respecto de las normas organizativas como supuesto en el que puede prescindirse de los trámites de audiencia e información públicas, precisamente por tratarse de normas que no afecten a los derechos e intereses mencionados, como luego se verá.

En nuestra opinión, la nueva regulación básica contenida en el artículo 133.2 de la LPAC parece vincular tanto el trámite de audiencia como el de información pública a la circunstancia de que el proyecto normativo "afecte a los derechos e intereses legítimos de las personas», pues liga dicha circunstancia a la práctica por el centro directivo competente de la publicación del proyecto, con el objeto de dar audiencia a los ciudadanos afectados «y» recabar cuantas aportaciones adicionales puedan hacerse por otras personas o entidades. Es decir, como se deduce del empleo de la conjunción copulativa "y», se elimina para el trámite de información pública la posibilidad de valoración de su procedencia

48 Sobre esta cuestión puede verse el Dictamen 275/2015 del Consejo de Estado.

49 «Ciertamente, es a partir de 1985, sin perjuicio de que existieran precedentes más remotos (v. gr. STS de 16 de may. 1972 - Ar.2971 - y de 22 dic. 1982 —Ar.8081-), cuando la configuración del trámite como preceptivo o de observancia obligatoria se intensifica en los pronunciamientos jurisprudenciales (por todas, STS de 18 dic. 1985 —Ar. 6539— [...]» P. SALA ATIENZA (2008: 249).

50 J. A. RAZQUiN LiZÁrRaGa (2007: 231). 
en atención «a la naturaleza de la disposición» y se exige su práctica preceptiva junto con la audiencia cuando esta, a su vez, sea exigible, fuera de este caso entendemos podrá practicarse de forma facultativa aunque el precepto mencionado no se refiere a ello, sin perjuicio de lo que establezca al respecto la legislación de las comunidades autónomas y entidades locales.

Por ejemplo, si se trata de una norma interna de carácter organizativo, podemos entender que no afecta a los derechos e intereses legítimos de los ciudadanos, por lo tanto, no será necesario dar participación a la ciudadanía conforme a lo previsto en el artículo 133 de la LPAC. Ello no impide, no obstante, que la Administración decida atendiendo a las circunstancias del caso concreto, realizar un trámite de información pública. En cambio, si se trata de una norma que afecta a los derechos de los ciudadanos, por ejemplo, una norma reguladora del comercio minorista, deberá de forma preceptiva someterse al trámite de audiencia de los ciudadanos que pudieran verse afectados - de forma directa y, en su caso, a través de las organizaciones o asociaciones reconocidas por la ley-, además, de forma acumulativa, se someterá al trámite de información pública para que los demás ciudadanos, los no directamente afectados, puedan participar y formular observaciones al respecto.

Esta nueva regulación del trámite de información pública dificulta su diferenciación con el de audiencia, pues antes aquel era facultativo en los casos en que la naturaleza de la disposición así lo aconsejara, si bien, al eliminarse esta característica y exigirse su convocatoria de forma preceptiva en los mismos supuestos de la audiencia, dificulta la diferencia de ambos trámites, sin perjuicio de las singularidades que puedan establecerse en las correspondientes disposiciones de las comunidades autónomas y de las entidades locales.

Antes de continuar con el análisis de estos trámites conviene hacer un breve repaso a la doctrina del Tribunal Supremo en esta materia, para lo que seguiremos principalmente el resumen contenido en la Sentencia 418/2010, de 15 de abril, Sala de lo Contencioso-Administrativo, Sección $2^{a}$, del Tribunal Superior de Justicia de Galicia:

i) El procedimiento de elaboración de reglamentos sirve de garantía ad intra, de legalidad y acierto de la norma proyectada, y de garantía ad extra, de protección de los derechos de los ciudadanos:

El procedimiento de elaboración de los reglamentos [...] supone un límite formal al ejercicio de la potestad reglamentaria. Su observancia tiene un carácter ad solemnitate, de modo que conforme a reiterada jurisprudencia 
del Tribunal Supremo la omisión del procedimiento o un defectuoso cumplimiento que se traduzca en una inobservancia transcendente para el cumplimiento de la finalidad a que tiende su exigencia, arrastra la nulidad de la disposición que se dicte, orientación teleológica que tiene una doble proyección: una garantía ad extra en la que se inscribe tanto la audiencia de los ciudadanos a través de las organizaciones previstas en el artículo 24.1.c de la Ley de Gobierno como la necesidad de una motivación, en la medida necesaria para evidenciar que el contenido discrecional que incorpora la norma no supone ejercicio arbitrario de la potestad reglamentaria y otra garantía interna para asegurar la legalidad y acierto que son los informes y dictámenes preceptivos a que se refiere el artículo 24.1.b ) LG (sentencia de la sección $6^{\mathrm{a}}$ de 16 de diciembre de 2008, sentencia de la Sala Tercera, sección $2^{\text {a }}$, de 1 de octubre de 2009).

ii) El trámite de audiencia se configura como un requisito de validez de la norma: la audiencia prescrita por el artículo 24.l.c) de la Ley 50/1997 no es una mera formalidad accesoria sino «requisito y garantía esencial ligada a la validez del resultado del procedimiento elaborativo».

iii) El trámite de audiencia tiene por finalidad plasmar en el ámbito del procedimiento de elaboración de disposiciones administrativas el principio de participación ciudadana:

El artículo 24 de la Ley del Gobierno ofrece un amplio elenco de posibilidades para alcanzar dicho objetivo: la audiencia directa a los afectados, la audiencia a través de asociaciones u organizaciones representativas, la solicitud a estas de informes o estudios y el sometimiento del proyecto de disposición a información pública (Sentencia de 16 de marzo de 2005, de la Sala de lo Contencioso-Administrativo, Sección $3^{\mathrm{a}}$ ).

iv) La consulta a asociaciones debe practicarse a las que sean titulares de un interés legítimo que se vean directa y negativamente afectados por la norma proyectada:

Es decir, cuando se trata de sujetos asociativos con un interés cualificado que se ven directa, inmediata y negativamente afectados por el nuevo reglamento, [...] dichos sujetos son suficientemente conocidos por la Administración (o, a fortiori, han sido previamente interlocutores de esta en relación con la materia normativa correspondiente) - Sentencia de la sección $3^{\mathrm{a}}$ de 2 de diciembre de 2008 dictada en el recurso 1997/2006.

v) Adicionalmente, la consulta debe practicarse a las asociaciones «reconocidas por la ley» que «agrupen o representen» a las personas 
cuyos derechos o intereses legítimos se vieren afectados por la normas y cuyos fines guarden relación directa con su objeto, aun cuando sean asociaciones voluntarias.

Este Tribunal ha afirmado (Sentencia 19 de enero de 1991, 11 de abril de 2000) que no habían de ser oídas cuantas asociaciones se constituyan, sino las asociaciones o colegios profesionales que no sean de carácter voluntario y representen intereses de carácter general o corporativo, naturaleza de representación legal que ostenta la parte recurrida en casación, por cuanto la preceptividad de la audiencia excluye las asociaciones de carácter voluntario (STS 6 de julio de 1999). No obstante también ha sostenido (STS 27 de mayo de 2002) que, dado que la finalidad del precepto es hacer efectivo en el orden material o de la realidad de las cosas el principio de participación que en este aspecto recoge el artículo 105 de la Constitución, nada impide que dicha audiencia pueda ser llevada a cabo, si este procedimiento aparece como adecuado en función de las circunstancias, recabando el informe de una entidad de afiliación voluntaria que agrupe a todos los colegios afectados (STS de 6 de junio de 2004).

vi) Las observaciones formuladas en el trámite de audiencia e información públicas no son vinculantes para la Administración:

Audiencia cuyo significado es que las organizaciones representativas, a que se refiere el art. $105 \mathrm{CE}$, sean escuchadas en el correspondiente trámite de alegaciones mas, como reiteradamente declara la jurisprudencia, en modo alguno puede comportar que los citados alegatos o sugerencias deban ser asumidos en todo o en parte (STS de 9 de junio de 2004).

vii) El trámite de audiencia no garantiza a los administrados un derecho a alegar en una fase última e inmediata a la aprobación de la norma: "Así resulta de la sentencia de esta Sala de 30 de junio de 1999, y de la naturaleza de los trámites de información pública y de audiencia recogidos en el artículo 130.4 y 5 LPA».

De lo expuesto, podemos extraer las siguientes conclusiones respecto del marco de la nueva regulación estatal contenida en el artículo 133 sobre la participación de los ciudadanos en el procedimiento de elaboración de reglamentos:

a) La finalidad principal de ese precepto, como lo fue el anterior artículo 24 y el actual artículo 26 de la LG, para la Administración General del Estado y para las comunidades autónomas que no han aprobado un procedimiento propio de elaboración de normas, es cumplir con la 
exigencia constitucional contemplada en el artículo 105 a), plasmando en este ámbito el principio de participación de los ciudadanos «directamente o a través de las organizaciones y asociaciones reconocidas por la Ley». Asimismo, como indica la exposición de motivos, la finalidad de la nueva regulación contenida en la LPAC es incrementar la participación de los ciudadanos en el procedimiento de elaboración de normas, para lo cual configura un nuevo trámite, previo al inicio del procedimiento que es la consulta pública.

b) La finalidad específica de la consulta pública es conocer la opinión de los «sujetos y las organizaciones más representativas potencialmente afectadas» acerca de problemas que se pretenden solucionar con la iniciativa, la necesidad y oportunidad de su aprobación, los objetivos de la norma y las posibles soluciones alternativas regulatorias y no regulatorias, lo que, a su vez, sirve para constatar la necesidad y oportunidad de su aprobación. La delimitación de los sujetos a quienes debe consultarse se efectúa con el sustantivo «sujetos» y «organizaciones más representativas» que puedan verse «potencialmente afectados» por la futura norma, por lo que parece que incluye también a los sujetos públicos, es decir, a otras administraciones públicas, salvo que «sujetos» se refiera a «ciudadano» como dice el artículo 133.2 para el supuesto del trámite de audiencia.

c) Se regulan, por primera vez, en una norma estatal de carácter básico los trámites de audiencia e información públicas, los cuales se configuran como trámites preceptivos en los supuestos en los que la norma «afecte a los derechos e intereses legítimos de las personas», debiéndose practicar de forma acumulativa. En los casos en los que la norma proyectada no tenga incidencia sobre los derechos e intereses legítimos de las personas, la LPAC no dice nada, lo que no obsta a que pueda practicarse el trámite de información pública con carácter facultativo, de acuerdo con lo que determine al respecto la legislación de las comunidades autónomas o de las entidades locales.

Cuando la norma afecte a los derechos e intereses legítimos de las personas, se deberá dar audiencia directamente a los «ciudadanos afectados» $\mathrm{y}$, «asimismo», podrá también recabarse directamente ${ }^{51}$ la opinión de «las organizaciones y asociaciones reconocidas por ley que agrupen o representen a las personas cuyos derechos o intereses legítimos se vieren afectados por la norma y cuyos fines guarden relación directa con su objeto", ya sean de constitución obligatoria o voluntaria. Sin duda, el adverbio "asimismo» empleado tiene un carácter acumu-

51 Véase J. A. Santamaría Pastor (2016: 43). 
lativo y no alternativo. Por lo tanto, a diferencia de lo que se ha venido entendiendo hasta ahora, la audiencia se practicará directamente a los ciudadanos y, en su caso, también a las organizaciones y asociaciones reconocidas por la Ley, a pesar de la claridad de la redacción del artículo 105.a) de la CE cuando dice «directamente o a través de las organizaciones y asociaciones reconocidas por la Ley». Por otra parte, el precepto no alude a la conocida como «audiencia institucionalizada» ${ }^{52}$, es decir, a los supuestos en los que se realiza a través de consejos que ejercen una función de representación de un determinado sector económico o social.

Las alegaciones, las sugerencias o los argumentos expuestos por los interesados en los trámites de participación ciudadana no vinculan a la Administración, en palabras de la jurisprudencia citada supra, "en modo alguno puede comportar que los citados alegatos o sugerencias deban ser asumidos en todo o en parte». Todo lo cual, dice MuÑoz MA$\mathrm{CHADO}^{53}$ :

no permite que el órgano que instruye el procedimiento se desentienda de las alegaciones y no les preste ninguna consideración. Tiene que poder probar, por el contrario, que las ha estudiado seriamente. Esta obligación, apenas tenida en cuenta entre nosotros, es decisiva para la validez del reglamento en la jurisprudencia estadounidense (doctrina del hard look, relativa, precisamente, al deber de examinar seriamente los resultados de la participación ciudadana $)^{54}$.

d) El Tribunal Supremo ha entendido, como se ha explicado, que el procedimiento de elaboración de normas constituye un límite formal a la potestad reglamentaria y que su observancia tiene carácter «ad solemnitatem», de modo que «la omisión del procedimiento o un defectuoso cumplimiento que se traduzca en una inobservancia transcendente para el cumplimiento de la finalidad a que tiende su exigencia, arrastra la nulidad de la disposición». Esta doctrina es, por lo tanto, aplicable a los

52 Sobre la audiencia y los órganos en los que se encuentren representados los intereses del sector, puede verse E. MELero Alonso (2005: 382).

53 S. Muñoz Machado (2006), "La competencia y el procedimiento de elaboración de los reglamentos de las Administraciones estatal y autónoma», Tratado de Derecho administrativo y Derecho público general, t. II, El ordenamiento jurídico, Madrid: Iustel (pág. 973).

54 «En este extremo, y asumiendo el riesgo que toda generalización inevitablemente conlleva, puede afirmarse que la práctica de la Administración General del Estado es satisfactoria, pues en la actualidad obra en muchas ocasiones en el expediente un documento habitualmente denominado informe al trámite de audiencia, en la que se resumen las alegaciones principales formuladas por los afectados y se expresa - bien que en muchas ocasiones en términos apodícticos, sin justificación de la decisión- si las mismas se aceptan o no», J. J. LAVILLA RUBIRA (2009: 28). 
trámites de garantía de la participación de los ciudadanos configurados en el artículo 133 de la LPAC, por lo que su omisión o defectuoso cumplimiento puede acarrear la nulidad de la norma. Conclusión que parece no plantea dudas para el supuesto de los trámites de audiencia e información públicas, no así, como se ha explicado, para la omisión o defectuoso cumplimiento del trámite de consulta pública por la razón de que se trata de un trámite previo al inicio del procedimiento y porque su finalidad puede realizarse a través del trámite de audiencia e información públicas.

Este esquema normativo de carácter básico, cuya finalidad es garantizar la participación ciudadana en el ámbito de la iniciativa legislativa y del ejercicio de la potestad reglamentaria, constituye sin duda un avance $^{55}$ en el impulso o facilitación de la participación ciudadana en los procedimientos de elaboración de las normas: por un lado, porque permite la participación de todos los afectados (trámite de audiencia) y de todos los que tengan interés en participar (trámite de información pública); por otro lado, exige que dicha participación se produzca de forma telemática, a través del portal web. No obstante, se echan en falta las correspondientes previsiones sobre la obligación de que las observaciones formuladas en estos trámites sean al menos respondidas en la correspondiente memoria, carencia que por supuesto puede ser suplida por la legislación de desarrollo de las comunidades autónomas y de las entidades locales.

\section{Requisitos para la práctica de la consulta, audiencia e información públicas}

De acuerdo con lo dispuesto en el artículo 133.3 de la LPAC:

La consulta, audiencia e información públicas reguladas en este artículo deberán realizarse de forma tal que los potenciales destinatarios de la norma y quienes realicen aportaciones sobre ella tengan la posibilidad de emitir su opinión, para lo cual deberán ponerse a su disposición los documentos necesarios, que serán claros, concisos y reunir toda la información precisa para poder pronunciarse sobre la materia.

Tal y como exige en sus apartados 1 y 2, dichos trámites se realizarán a través del portal web ${ }^{56}$ de la Administración competente, que se con-

\footnotetext{
55 Véase J. A. Santamaría Pastor (2016: 40-41)

56 Véase J. A. Santamaría Pastor (2016: 43).
} 
vierte de este modo en un medio de publicidad específico para este fin, desplazando la publicación tradicional en los diarios oficiales correspondientes, que entendemos podrán utilizarse facultativamente como medio de publicidad complementario.

Para la práctica correcta de dichos trámites deberá ponerse a disposición los documentos necesarios, que deben ser claros, concisos y reunir toda la información precisa para poder pronunciarse sobre la materia. Entendemos que la puesta a disposición debe efectuarse también a través del portal web, salvo cuando ello resulte técnicamente imposible, en cuyo caso se indicará el lugar en que se encuentre accesible.

Por su parte, el artículo 26.2 de la LG, en el ámbito de la Administración General del Estado, indica que la consulta pública se sustanciará, "a través del portal web del departamento competente, con carácter previo a la elaboración del texto, en la que se recabará opinión de los sujetos potencialmente afectados por la futura norma y de las organizaciones más representativas» acerca de las cuestiones indicadas en el artículo 133.1, es decir, en resumen, sobre la necesidad y oportunidad de su aprobación.

Asimismo, el artículo 26.2 LG indica que la consulta pública deberá realizarse de tal forma que todos los potenciales destinatarios de la norma tengan la posibilidad de emitir su opinión, para lo cual deberá proporcionarse un tiempo suficiente, que en ningún caso será inferior a quince días naturales.

Respecto de la audiencia e información públicas, el artículo 26.6 de la LG emplea la misma redacción que el artículo 133.2 de la LPAC y precisa que, sin perjuicio de la consulta previa a la redacción del texto de la iniciativa, cuando la norma afecte a los derechos e intereses legítimos de las personas, el centro directivo competente publicará el texto en el portal web correspondiente, con el objeto de dar audiencia a los ciudadanos afectados y obtener cuantas aportaciones adicionales puedan hacerse por otras personas o entidades. Asimismo, podrá recabarse directamente la opinión de las organizaciones o asociaciones reconocidas por ley que agrupen o representen a las personas cuyos derechos o intereses legítimos se vieren afectados por la norma y cuyos fines guarden relación directa con su objeto.

A ello añade que el plazo mínimo de esta audiencia e información públicas será de 15 días hábiles, y podrá ser reducido hasta un mínimo de siete días hábiles cuando razones debidamente motivadas así lo justifiquen; así como cuando se aplique la tramitación urgente de iniciativas normativas, tal y como se establece en el artículo 27.2. De ello deberá dejarse constancia en la Memoria del Análisis de Impacto Normativo. 
En el supuesto de tramitación por vía de urgencia del procedimiento de elaboración de reglamentos, se reducirán a la mitad de los plazos previstos para la realización de los diferentes trámites, además, dice el artículo 27.2 LG, no será preciso el trámite de consulta pública, «sin perjuicio de la realización de los trámites de audiencia pública o de información pública sobre el texto a los que se refiere el artículo 26.6, cuyo plazo de realización será de siete días».

4. Supuestos excluidos de la realización de los trámites de consulta, audiencia e información públicas

El artículo 133.4 de la LPAC permite prescindir del trámite de consulta pública ${ }^{57}$ cuando medie alguna de las siguientes razones:

a) Cuando la propuesta normativa no tenga un impacto significativo en la actividad económica.

b) Cuando no imponga obligaciones relevantes a los destinatarios.

c) Cuando regule aspectos parciales de una materia.

d) En los casos de tramitación urgente, conforme a lo que disponga la normativa reguladora del ejercicio de la iniciativa legislativa o de la potestad reglamentaria.

De las causas expuestas, llama la atención el empleo de conceptos jurídicos indeterminados en casi todos los supuestos, así, cuando la norma «no tenga un impacto significativo» en la actividad económica, cuando «no imponga obligaciones relevantes», o regule «aspectos parciales» de una materia. Pensemos, por ejemplo, en un proyecto normativo de regulación de la tenencia y uso de armas, el cual, en principio, no tendrá per se un impacto significativo en la actividad económica, si bien se exigirá para la tenencia y uso de armas una licencia previa que podrá fundamentarse en razones de interés general como la seguridad de las personas o el orden público, pues esta exigencia de licencia previa resulta adecuada y proporcionada a dichos fines públicos. La pregunta que seguidamente debemos formulamos es si estas obligaciones pueden considerarse como «relevantes» para sus destinatarios, pues en caso afirmativo deberá practicarse el trámite de consulta pública, en caso negativo puede fundamentarse en la memoria la no procedencia de dicho trámite.

57 A. J. Alonso Timón (2016: 82). 
Los casos de tramitación de urgencia del procedimiento de elaboración de las disposiciones administrativas permite también la exclusión del trámite de consulta previa, si bien, en este caso, la LPAC se remite a la normativa reguladora del ejercicio de la iniciativa legislativa o de la potestad reglamentaria, la cual puede acordar, por ejemplo, como en el caso de la audiencia e información públicas, reducir su plazo a la mitad u otra regla similar.

Por su parte, el apartado cuarto del precepto mencionado precisa otros dos supuestos en los que podrá prescindirse del trámite de consulta, si bien sirven también para justificar la exclusión de los trámites de audiencia e información públicas. Estas causas son:

a) Cuando se trate de normas presupuestarias u organizativas.

b) Cuando concurran razones graves de interés público que lo justifiquen.

En el primer supuesto, sin duda, queda claro que la exclusión se produce por la naturaleza interna de las normas organizativas, con escasos o nulos efectos sobre la ciudadanía - pensamos en las normas típicas de organización y estructuras de las administraciones públicas-. En el segundo supuesto, el de las normas presupuestarias, la exclusión parece que encuentra su fundamento en su naturaleza y contenido especial —aprobación anual de los gastos e ingresos-, en la necesidad de su aprobación en un periodo de tiempo determinado, etc.; no obstante, nótese que en el ámbito de las entidades locales, tanto el proyecto de presupuestos como las ordenanzas fiscales se someten a información pública $^{58}$, debiéndose contestar las observaciones que se formulen en la correspondiente memoria.

Por último, otra causa que permite excluir estos trámites de participación ciudadana en el procedimiento de elaboración de disposiciones administrativas es la concurrencia de «razones graves de interés público» que lo justifiquen, de nuevo el empleo de un concepto jurídico indeterminado para concretar el supuesto habilitante de la exclusión que, en este caso, debe tratarse de razones de interés público que puedan calificarse como "graves», lo cual exige un esfuerzo de motivación en la correspondiente memoria de análisis de impacto normativo.

58 Véase el artículo 17 del Real Decreto Legislativo 2/2004, de 5 de marzo, por el que se aprueba el texto refundido de la Ley Reguladora de las Haciendas Locales; el artículo 169 de la Ley Reguladora de las Haciendas Locales respecto de la tramitación de sus presupuestos generales y el artículo 48.3 de la Ley 22/2006, de 4 de julio, de Capitalidad y del Régimen Especial de Madrid. 


\section{Conclusiones}

El título VI de la LPAC establece un nuevo ciclo normativo (planificación normativa, principios de buena regulación, participación ciudadana, publicidad en boletines digitales y evaluación posterior), del cual hemos analizado en el presente trabajo las partes esenciales del procedimiento para el ejercicio de la iniciativa legislativa y la potestad reglamentaria. De esta regulación del procedimiento normativo podemos resaltar, a modo de conclusión, las siguientes ideas.

En primer lugar, es de sentido común que las normas incorporen los motivos principales que la justifican, debiéndose abandonar definitivamente esa mala práctica consistente en la incorporación de ideas generales para explicar su sentido y finalidad. Además, la motivación debe contener las explicaciones necesarias para justificar los contenidos de la norma, los cuales deben fundamentarse en los principios de necesidad, eficacia, proporcionalidad, seguridad jurídica y eficiencia, de lo que se deducirá que la nueva norma resulta necesaria y proporcionada y, consecuentemente, respetuosa con el principio constitucional de interdicción de la arbitrariedad de los poderes públicos.

En segundo lugar, el impulso de la participación ciudadana es uno de los objetivos de esta nueva regulación, si bien ya contaba con un instrumento adecuado para garantizar su efectividad a través de los trámites de audiencia e información públicas, no obstante, la realidad nos dice que la participación real en dichos trámites es muy baja, por ello quizá no se trataba tanto de establecer otros cauces de participación como el de consulta previa, sino hacer efectivos los existentes, prestándoles la máxima atención por parte de las administraciones públicas convocantes, fomentándolos, ofreciendo canales de comunicación que la faciliten y contestando debida y adecuadamente las observaciones que se formulen y que no sean aceptadas.

En definitiva, la regulación del procedimiento para la elaboración de normas contenido en el título VI de la LPAC pretende consolidar la cultura de la buena administración orientada a la calidad normativa, con la finalidad última de garantizar los derechos de los ciudadanos y las empresas y la plena realización del interés general. Queda pendiente la tarea más compleja: hacerla realidad. 